\title{
Management of Highway Projects in Egypt through Identifying Factors Influencing Quality Performance
}

\author{
Ahmed Ebrahim Abu El-Maaty, Ahmed Yousry Akal, and Saad El-Hamrawy \\ Civil Engineering Department, Faculty of Engineering, Menoufia University, Menoufia, Egypt \\ Correspondence should be addressed to Ahmed Ebrahim Abu El-Maaty; maaty5000@yahoo.com
}

Received 2 April 2016; Accepted 19 July 2016

Academic Editor: Eul-Bum Lee

Copyright ( 2016 Ahmed Ebrahim Abu El-Maaty et al. This is an open access article distributed under the Creative Commons Attribution License, which permits unrestricted use, distribution, and reproduction in any medium, provided the original work is properly cited.

\begin{abstract}
While project management success focuses upon the processes and the successful accomplishments of cost and time objectives, product success deals with the quality of the final product. Recently, quality of the constructed highway has been considered highly important reason for the pavement response and its design life. The main objective of this paper is to improve the management of highway projects in Egypt by determining the most important factors influencing the quality performance of this industry. In total, 39 factors that may influence the quality of highway projects have been defined through a detailed literature review. The factors are tabulated in a questionnaire form, which is sent out to 13 owners of divided highways, 27 owners of regional roads, and 15 consultants. The analysis of the respondents' perspectives using fuzzy triangle approach shows that the most important factors affecting the quality are availability of experienced staff in the owner's and contractor's teams during the project execution; efficiency of the owner's inspection team; clarity of responsibilities and roles for each owner, consultant, and contractor; pavement which is not designed according to the regional conditions (e.g., soil type, temperature, and traffic volume); and asphalt quality and type used in the construction process.
\end{abstract}

\section{Introduction}

Quality is a key function in all infrastructure development environment like cost and time [1]. In highway construction industry, quality is a major factor in determining how well a pavement will perform under traffic loading and when subjected to environmental influences [2]. Furthermore, it provides a tool to the owner and contractor to ensure that the desired results are obtained to produce high-quality and long-life pavements [3]. In highway construction projects, the ultimate aim of an owner is to build a pavement that will have good serviceability under the local conditions of climate and traffic that the pavement will be exposed to during its anticipated life and result in minimum overall costs [4].

A highway asphalt concrete pavement's performance is a function of the pavement quality which is affected by many interacting factors such as pavement's structural design, construction materials, and the process by which these materials are built into the pavement. Pavement deteriorates with the passage of time and the rate of deterioration varies widely depending upon the above-mentioned factors and the amount of maintenance performed by the highway agency during the service life of the pavement. However, good quality of construction will reduce the rate of deterioration as much as possible [5].

There are many factors throughout the project's design and construction phases, which may affect the quality of the constructed highway. The project owner agency, consultant, and contractor organization should be aware of these factors and their relation to the final pavement quality so that the highway is designed and constructed with the objectives of achieving the desired quality. Through the present study factors influencing the quality of highway projects in Egypt will be discussed in order to

(1) identify the factors and groups which may affect the quality of highway projects, 
(2) specify the effectiveness degree of the identified factors using fuzzy triangle approach,

(3) determine the most important factors influencing the quality from the perspectives of the owners and consultants of highway projects in Egypt,

(4) provide recommendations for the achievement of good quality in the construction of highway projects in Egypt.

\section{Literature Review}

A number of studies have been conducted to identify factors influencing quality in construction projects. Bubshait [6] concluded that various parameters directly and indirectly contribute to the highway quality performance. The contributing factors are design, specifications, environment, and construction-related factors, while the indirect factors are managerial-related factors. Rustom and Amer [7] in Gaza strip noted that quality of construction projects is significantly affected by the characteristics of site layout, experience of site staff, consistency of design documents, the financial power of the contractor, and availability of construction materials.

Al-Hassan [5] conducted a study to determine the factors that contribute to the quality of pavement performance in Saudi Arabia. The study had been achieved via both a comprehensive literature review and a highway contractor's survey. Fifty-nine factors were explained and ranked according to their effectiveness index. Analysis of this study showed that the top five factors affecting the pavement quality and their effectiveness index were greater than $90 \%$ which were pavement not designed to the regional conditions, consistency of specification interpretation of aggregate quality, aggregate quality, amount of filler materials in the mixture, and availability of the specified material quality.

Kaliba et al. [8] conducted another study in Zambia in order to highlight the casual factors of quality shortfalls in its construction projects. The study method included the use of structured interviews and questionnaire survey questions. The results of the structured interviews showed that the main common causes of quality shortfalls in construction projects were identified to include corruption, lack of qualified personnel on site, lack of motivation amongst site personnel, lack of reliable sources of materials, poor quality control, and lack of adequate supervision.

Larsen et al. [9] studied 26 factors affecting the performance of quality in public construction projects in Denmark. The analysis of this study had been determined through a questionnaire survey which was sent to 111 project managers; only 56 project managers filled the questionnaire. Furthermore, the relative importance index method (RII) had been used here to rank factors with an index range of 0.0-1.0. The results of the study showed that errors or omissions in construction work is found to be the highest ranking followed by inexperienced or newly qualified consultants, political focus on reduced project costs or time, unsettled or lack of project planning, and errors or inconsistencies in project documents.
Jha and Iyer [10] identified the reasons for the underperformance of the quality of Indian construction projects. They identified 55 attributes responsible to impact quality performance of the projects. Out of this, conflict among project participants, hostile socioeconomic environment, harsh climatic condition, PM's ignorance and lack of knowledge, faulty project conceptualization, and aggressive competition during tendering were the most important factors that adversely affected the quality performances of construction projects in India. Furthermore, Arditi and Gunaydin [11] found that the main factors influencing the quality of construction projects during the construction phase are management leadership, supervision by contractor, cooperation of parties, management commitment, and selection of contractor.

\section{Need for the Study}

The construction industry in Egypt accounts for $4.7 \%$ of Egypt's Gross Domestic Product (GDP), making it one of the most important industries for the country's economic progress. For developing economies, highway construction constitutes a major component of the construction industry. Egypt's road network comprises 91,173 kilometers of roads, divided into 67,728 of main roads and 23,445 kilometers of artery roads. Furthermore, the roads network in Egypt carry out $85 \%$ of domestic freight and $60 \%$ of passenger movement, which makes it one of the most important industries affecting the GDP $[12,13]$. Furthermore, the investments in infrastructure especially highway project reach to US $\$ 5.46$ billion which means that much of the national budget on infrastructure development in Egypt is channelled to highway construction projects $[14,15]$.

However, the importance of such industry in Egypt to the national economy is that most of highway projects in Egypt are not at the desired level of quality. For instance, according to a report by the World Bank, only $20 \%$ of the roads in Egypt are in good condition and suffering from low service quality and are at risk of premature failure [16]. This problem may be a result of several causes and, consequently, the identification and consideration of these causes in future highway construction will lead to better pavement performance, longer service life, and lower maintenance costs.

In Egypt, a number of studies were carried out to identify factors influencing quality in construction projects. More or less all were focused on building projects or construction projects of all types except highway projects [17-19]. For that, it is of key importance to exert the utmost effort to accomplish such study, in order to identify the various factors affecting the quality of the highway projects in Egypt from the local highway owner's and consultant's points of view since they are the ones who supervise the construction process of the highway network in Egypt.

\section{Research Methodology}

This research is on the basis of a survey designed to gather all necessary information in an effective way. The survey presents 39 factors that may influence the highway projects quality performance. A questionnaire was developed to 
evaluate the effectiveness degree of the identified factors. The studied target population includes the owners of divided highways and main roads, owners of regional roads, and consultants of highway projects in Egypt. Datawere gathered through a survey and analyzed by using fuzzy triangular approach.

\section{Questionnaire Design}

The questionnaire consists of two parts. The first part includes general information questions about the respondents such as his/her name (optional) and relevant working experience. The second part lists 39 factors that impact the quality level of highway projects in Egypt (13 management-related factors, 13 design and specifications-related factors, and 13 construction process-related factors). Table 1 shows the identified factors and their related groups.

\section{Calculation the Effectiveness Degree of the Identified Factors}

In the current study, the identified factors have been explained and ranked according to their medium fuzzy effectiveness value through the application of fuzzy triangular approach. The respondents chose one out of four possible answers representing varying degrees of effect, on a scale of 1 to 4 . A response of 1 means the factor is ineffective, 2 means the factor has medium effect, 3 means the factor is effective, and 4 means the factor is very effective. The questionnaires have been analyzed and the medium fuzzy effect has been calculated for each factor using the following steps:

(1) Each factor will be fuzzified according to its weighted degree of severity effect received from questionnaire responses.

(2) Determine the minimum, medium, and maximum effectiveness value of each factor.

(3) Determine the membership of each effect according to its weighted degree of severity effect.

(4) Forming a triangular membership function of each factor.

The following is an example for illustrating the previous steps. For instance, Factor number 3.1 "availability of experience staff in the owner and contractor team during the project execution" which has been fuzzified by the owners of divided highways and main roads in Egypt is as follow. The responses related to this factor from the respondents are 12 for very effective, 1 for effective, 0 for medium effect, and 0 for ineffective. Accordingly, the weighted degrees of severity effect are $[(12 \times 4) /(4 \times 13)] \times 100=92.31 \%,[(1 \times 3) /(4 \times$ $13)] \times 100=5.77 \%,[(0 \times 0) /(4 \times 13)] \times 100=0.0 \%$ and $[(0 \times 0) /(4 \times 13)] \times 100=0.0 \%$ for $(4 / 4)=1,(3 / 4)=0.75$, $(2 / 4)=0.50$, and $(1 / 4)=0.25$ memberships, respectively.

The next step is to determine the medium effect for Factor number 3.1 as follows: medium effect $=(92.31+5.77+0+$ $0) / 4=24.52 \%$. Figure 1 shows the minimum, medium, and maximum effects for Factor number 3.1. According to the

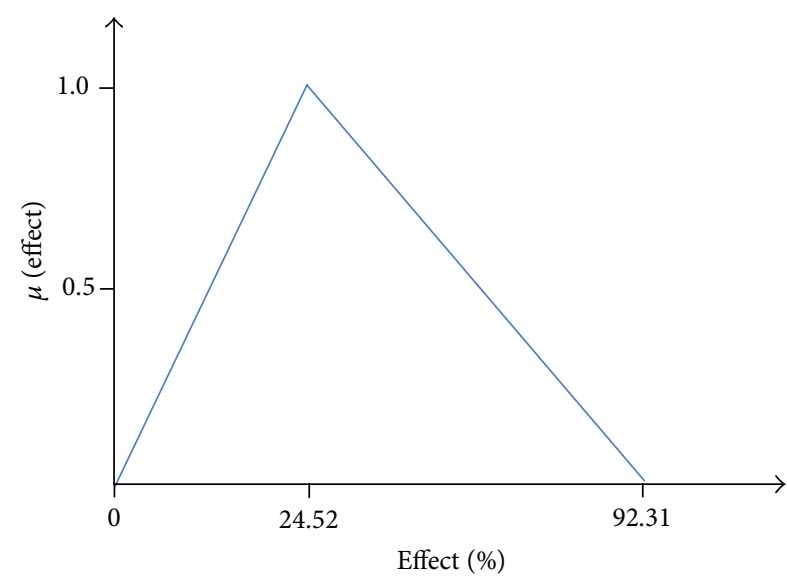

FIGURE 1: Fuzzy effectiveness values of Factor number 3.1 on quality performance.

shown figure, the minimum value among participants (owners of divided highways and main roads) is $0.0 \%$, the medium value is $24.52 \%$, and the maximum is $92.31 \%$.

\section{Research Findings and Results}

7.1. General Characteristics of Respondents. The questionnaire was sent out 13 owners of divided highways and main roads, 27 owners of regional roads, and 15 consultants. The responses rates of the limited population are $100 \%$ for the owners of divided highways and main roads, owners of regional roads, and consultants. These high responses rates indicate the significance of the study and reflect the amount of the existing problems in the Egyptian highways construction industry. Furthermore, all the participants in the survey have an average of more than 10 years of experience in the supervision of highway project in Egypt.

7.2. Factors Influencing Quality Performance. The result of the questionnaire is shown in Tables 2, 3, and 4. The factors that are believed to affect quality performances are listed with their medium fuzzy effectiveness value. The three groups of factors (managerial, design and specifications, and construction process) are discussed in the following paragraphs.

7.2.1. Managerial-Related Factors. Table 2 shows the medium fuzzy effect of each factor under the managerial group from the perspectives of owners of divided highways and main roads, owners of regional roads and consultants, and their collective view, that is, combination of owners' and consultants' views. Table 2 shows that the medium fuzzy effectiveness values as identified by owners of divided highways and main roads, owners of regional roads, and consultants are not similar. It is clear from this table that the medium fuzzy effectiveness values from the collective view have a wide span; it ranges from $23.18 \%$ to $15.57 \%$. The results also show that the most important factor which contributes the quality of highway projects from all views is Factor number "1.3 efficiency of the owner's inspection team." 
TABLE 1: Factors influencing quality level of highway projects.

\begin{tabular}{|c|c|}
\hline Sr. & Effective factor \\
\hline 1 & Group (1): managerial-related factors \\
\hline F1.1 & Clarity of responsibilities and roles for each owner, consultant, and contractor \\
\hline F1.2 & Develop a clear and detailed program for quality management to be adhered to by the owner, consultant, and contractor \\
\hline F1.3 & Efficiency of the owner's inspection team \\
\hline F1.4 & Assignment of quality control responsibility to the consultant \\
\hline F1.5 & Technical assessment of the contractor during the bidding process \\
\hline F1.6 & Selection of the lowest bidder to construct the project \\
\hline F1.7 & Contractor's past experience \\
\hline F1.8 & Contractor's financial status during the project execution \\
\hline F1.9 & Amount of work subcontracted \\
\hline F1.10 & Contractor's labors and equipment capability \\
\hline F1.11 & Cost escalation of resources (materials, labors, and equipment) needed to achieve the required quality level \\
\hline F1.12 & Unavailability of financial incentive to the contractor to produce higher level of quality \\
\hline F1.13 & Delay in contactor progress payment \\
\hline 2 & Group (2): design and specifications-related factors \\
\hline F2.1 & Pavement is not designed according to the regional conditions (e.g., soil type, temperature, and traffic volume) \\
\hline F2.2 & Design errors arising from inadequate engineer assumptions and inaccurate data \\
\hline F2.3 & Insufficient owner involvement during the design phase (design evaluation, review, and updating design) \\
\hline $\mathrm{F} 2.4$ & Accuracy of investigation performed on soil type encountered \\
\hline F2.5 & Accuracy of data related to traffic volume, composition, and expected growth \\
\hline F2.6 & Use construction materials suitable for climate (temperature) \\
\hline F2.7 & Clarity and accuracy of specifications in relation to aggregates quality and gradation \\
\hline F2.8 & Clarity and accuracy of specifications in relation to asphalt quality and type \\
\hline F2.9 & Clarity and accuracy of specifications in relation to the required compaction level \\
\hline $\mathrm{F} 2.10$ & Overspecifying of materials and equipment to be used and construction method to be followed \\
\hline F2.11 & Limitation on materials sources, equipment type, and construction method imposed by specifications \\
\hline $\mathrm{F} 2.12$ & Job mix formula type used to produce asphalt mixture (open graded, dense graded, etc.) \\
\hline $\mathrm{F} 2.13$ & Asphalt mixture properties (e.g., stability, durability, and workability) \\
\hline 3 & Group (3): construction process-related factors \\
\hline F3.1 & Availability of experienced staff in the owner's and contractor's teams during the project execution \\
\hline F3.2 & Availability of the specified materials quality \\
\hline F3.3 & Asphalt quality and type used in the construction process \\
\hline F3.4 & Aggregates quality used in the construction process (e.g., gradation, shape, and type) \\
\hline F3.5 & Variation in aggregates gradation in stockpiles, mixing, transportation, and placement operation \\
\hline F3.6 & Variation in asphalt content during mixture operation \\
\hline F3.7 & Amount of filler materials in the mixture \\
\hline F3.8 & Continuous changing in mix design due to change in the nature and source of materials during construction phase \\
\hline F3.9 & The use of marginal materials in pavement constructed in regions of hot climate and heavy loading traffic conditions \\
\hline F3.10 & Condition of road bed soil \\
\hline F3.11 & $\begin{array}{l}\text { Uniformity of mixture placement and compaction operations constructed in regions of hot climate and heavy loading traffic } \\
\text { conditions }\end{array}$ \\
\hline F3.12 & Compacting pattern used to achieve the desired pavement density \\
\hline F3.13 & Paver and roller mechanical condition and type \\
\hline
\end{tabular}

7.2.2. Design and Specifications-Related Factors. Table 3 shows the medium fuzzy effect of each factor under the design and specification group. The analysis of the shown table presents that the top affecting factor on the quality of highway projects in Egypt from the owners of divided highway and main roads, owners of regional roads, and collective view is Factor number 2.1: "pavement is not designed according to the regional conditions (e.g., soil type, temperature, and 
TABLE 2: Medium fuzzy effect of factors of managerial group on quality in highway construction projects.

\begin{tabular}{|c|c|c|c|c|}
\hline Factor number & Owners of divided highways and main roads & Owners of regional roads & Consultants & Combined view \\
\hline F1.1 & 25 & 22.92 & 21.67 & 23.07 \\
\hline F1.2 & 24.52 & 22.22 & 21.67 & 22.61 \\
\hline F1.3 & 24.04 & 23.61 & 21.67 & 23.18 \\
\hline F1.4 & 18.75 & 20.37 & 21.67 & 20.34 \\
\hline F1.5 & 22.12 & 20.83 & 19.58 & 20.80 \\
\hline F1.6 & 15.87 & 15.28 & 15.83 & 15.57 \\
\hline F1.7 & 20.67 & 21.3 & 21.67 & 21.25 \\
\hline F1.8 & 23.08 & 20.83 & 20.83 & 21.36 \\
\hline F1.9 & 19.71 & 15.05 & 15 & 16.14 \\
\hline F1.10 & 23.56 & 23.61 & 21.67 & 23.07 \\
\hline F1.11 & 20.19 & 18.98 & 20 & 19.55 \\
\hline F1.12 & 19.71 & 15.97 & 18.33 & 17.50 \\
\hline F1.13 & 20.67 & 20.6 & 22.08 & 21.02 \\
\hline
\end{tabular}

TABLE 3: Medium fuzzy effect of factors of design and specifications group on quality in highway construction projects.

\begin{tabular}{|c|c|c|c|c|}
\hline Factor number & Owners of divided highways and main roads & Owners of regional roads & Consultants & Combined view \\
\hline F2.1 & 23.56 & 23.61 & 21.67 & 23.07 \\
\hline $\mathrm{F} 2.2$ & 22.12 & 21.99 & 20.42 & 21.59 \\
\hline $\mathrm{F} 2.3$ & 19.71 & 17.36 & 18.75 & 18.30 \\
\hline $\mathrm{F} 2.4$ & 20.19 & 18.75 & 22.08 & 20.00 \\
\hline F2.5 & 21.15 & 21.06 & 21.25 & 21.14 \\
\hline F2.6 & 23.08 & 21.53 & 20.42 & 21.59 \\
\hline $\mathrm{F} 2.7$ & 21.63 & 21.06 & 19.17 & 20.68 \\
\hline F2.8 & 23.08 & 23.15 & 19.17 & 22.05 \\
\hline F2.9 & 23.08 & 22.92 & 20.42 & 22.27 \\
\hline F2.10 & 20.19 & 16.90 & 16.25 & 17.50 \\
\hline F2.11 & 20.19 & 16.90 & 17.92 & 17.95 \\
\hline F2.12 & 20.19 & 18.98 & 18.33 & 19.09 \\
\hline F2.13 & 21.15 & 22.69 & 19.58 & 21.48 \\
\hline
\end{tabular}

TABLE 4: Medium fuzzy effect of factors of construction process group on quality in highway construction projects.

\begin{tabular}{|c|c|c|c|c|}
\hline Factor number & Owners of divided highways and main roads & Owners of regional roads & Consultants & Combined view \\
\hline F3.1 & 24.52 & 24.31 & 23.33 & 24.09 \\
\hline F3.2 & 23.08 & 22.45 & 20.83 & 22.16 \\
\hline F3.3 & 24.04 & 24.07 & 20.42 & 23.07 \\
\hline F3.4 & 22.60 & 21.99 & 21.67 & 22.05 \\
\hline F3.5 & 18.75 & 17.13 & 18.75 & 17.95 \\
\hline F3.6 & 23.56 & 19.91 & 21.25 & 21.14 \\
\hline F3.7 & 23.56 & 21.76 & 21.25 & 22.05 \\
\hline F3.8 & 19.71 & 18.52 & 19.17 & 18.98 \\
\hline F3.9 & 21.63 & 20.83 & 19.17 & 20.57 \\
\hline F3.10 & 20.19 & 19.91 & 18.75 & 19.66 \\
\hline F3.11 & 20.19 & 20.37 & 20.42 & 20.34 \\
\hline F3.12 & 22.12 & 21.53 & 20.00 & 21.25 \\
\hline F3.13 & 22.12 & 20.60 & 17.92 & 20.23 \\
\hline
\end{tabular}


TABLE 5: Top five factors influencing quality and related groups from combined view.

\begin{tabular}{lccc}
\hline Factor number & Medium fuzzy effect & Related group & \\
\hline F3.1 & 24.09 & Construction process & Rank \\
F1.3 & 23.18 & Managerial & 2 \\
F1.1 & 23.07 & Managerial & 3 \\
F2.1 & 23.07 & Design and specification & \\
F3.3 & 23.07 & Construction process & 4 \\
\hline
\end{tabular}

traffic volume)," while Factor number 2.4 "accuracy of investigation performed on soil type encountered" has been identified by the consultants as the most influential factor which contributes to the quality of highway projects in Egypt.

7.2.3. Construction Process-Related Factors. Table 4 shows the medium fuzzy effect of each factor under construction process group. Thirteen factors are identified under this group. The analysis of this table shows that the owners of divided highway and main roads, owners of regional roads, and consultants agree on one opinion that the quality of highway projects in Egypt is affected to a high degree by Factor number 3.1 "availability of experienced staff in the owner's and contractor's teams during the project execution."

7.3. Top Five Factors Influencing Quality Performance. Table 5 illustrates the ranking of the top five factors influencing quality of highway construction projects in Egypt and their related groups from the collective perspective of the owners' of divided highways and main roads, owners of regional roads, and consultants. It is shown that two factors are related to the construction process group, two to the managerial group, and one to the design and specifications group. The results also show that the most five important factors affecting the quality of highway projects in Egypt from the perspectives of all the respondents to the questionnaire are (1) availability of experienced staff in the owner's and contractor's teams during the project execution, (2) efficiency of the owner's inspection team, (3) clarity of responsibilities and roles for each owner, consultant, and contractor, (4) pavement is not designed according to the regional conditions (e.g., soil type, temperature, and traffic volume), and (5) asphalt quality and type used in the construction process.

\section{Discussions of Results}

This section discusses the results obtained in the earlier section for the most five important factors influencing quality of highway projects in Egypt from the collective view of owners of divided highways and main roads, owners of regional roads, and consultants.

8.1. Availability of Experienced Staff in the Owner's and Contractor's Teams during the Project Execution. The construction of mega projects such as highway projects is a very complex construction process and achieving the project objectives in terms of quality, time, and cost usually required qualified and experienced staff in the project construction team. The availability of experienced engineers in the owner's and contractor's teams is essential factor to achieve the quality standards of the project. For instances, the owner needs the experienced engineers to inspect the project's activities and make sure that the specifications of the contract are followed by the contractor's staff, while the contractor needs experienced engineers to manage these activities and achieve the desire of the client concerning the required quality.

8.2. Efficiency of the Owner's Inspection Team. The success or failure of the quality of a construction project depends highly on the roles the inspector plays during the construction phase [20]. Efficiency of the owner's inspection team has also been shown to have a major effect on the quality of the constructed highway project in Egypt as indicated by the owners of divided highways and main roads, owners of regional roads, and consultants in Table 5. This finding is consistent with that of Warsame [21] and also has been supported by Barnes [22] who suggested that having the client's inspector's work with the contractor to establish good quality control procedures before the work is done is much more effective than walking around after.

8.3. Clarity of Responsibilities and Roles for Each Owner, Consultant, and Contractor. Construction quality is the product of a team effort and it is the responsibility of the owner, contactor, consultant, and any one of their staff who may be involved. During the construction process, each team has a specific role to play in ensuring the quality of the project. A clear identification of the authorities, responsibilities, and roles of each party in the contract clauses will minimize misunderstanding and conflicts between the project stakeholders, and consequently, this will lead to a cooperation between the project parties in which more efforts are focused on constructing the project in accordance with the desired level of quality.

8.4. Pavement Is Not Designed according to the Regional Conditions (e.g., Soil Type, Temperature, and Traffic Volume). Effective pavement design is one of the more important aspects of project design [23]. The design of highway pavement is an important factor in controlling the final quality of the project. The design of flexible pavement is the process of selecting the pavement layer types and the thicknesses in order to withstand the expected traffic loads in a costeffective manner. This process involves studies of soils and paving materials, their behavior under loads, and the development of a pavement section to carry loads under all climatic conditions [24]. Therefore, in order to provide an adequate pavement performance for the required design life, 
the pavement cross section properties (materials types and thickness) must be determined with respect to the actual and anticipated traffic volume, the prevailing climatic conditions in the construction site, project's soil type, and reliable design procedures.

8.5. Asphalt Quality and Type Used in the Construction Process. Quality of asphalt and its type have been identified by the owners of divided highways and main roads, owners of regional roads, and consultants of highway projects in Egypt as one of the most important factors influencing the quality performance. According to Knuston [25] asphalt concrete pavement is only as good as the material and workmanship that go into it. Furthermore, the pavement could be penalized if the material used is of inferior quality. Quality of asphalt or bitumen material has a significant role in the performance of the whole highway project. Therefore, the proper selection and close control of asphalt material in terms of asphalt content, grade, and type will enhance the efficiency of the hot mix-asphalt, and, consequently, the quality of the highway project will be affected.

\section{Recommendations to Enhance Quality of Highway Construction}

According to the above-mentioned findings, the following points are recommended for the achievements of good quality performance in the Egyptian highway projects:

(1) The availability of qualified, experienced, and efficient staff in the owner's, consultant's, and contractor's teams is an important factor for monitoring and controlling over the outcome of the project and achieving the specified quality. Therefore, the stakeholders of highway projects in Egypt have to develop plans and programs for training their staff in order to improve their skills and qualifications through the presence of human resources department responsible for handling professionals and staff training.

(2) The construction industry consists of numerous parties: owner, contractor, and consultant each of which has a role to play in delivering a quality project. Therefore, the contract document should shape in a clear manner the contractual relationship between the project's parties in order to avoid any conflict/discrepancy.

(3) Detailed and comprehensive site investigation should be done during the design phase in order to collect accurate data about the design parameters such as soli type and temperature. Furthermore, allowing sufficient time for proper planning and design process will help the designers to avoid errors and omissions.

(4) Implementing an effective quality control and assurance systems during the construction process is recommended to be an effective way to assure the desired end product quality. This will help the project supervisors to periodically inspect the construction materials, check the constructed works, and make sure that the project quality is in accordance with its technical specifications.

\section{Summary and Conclusions}

The construction of highway projects is a complex process involving many critical phases during which factors that affect the quality of performance of the asphalt concrete pavement might be overlooked. The newly constructed highway projects in Egypt have exhibited a low quality of performance. There are various parameters that contributed to the quality of performance. It is concluded that there is a need to conduct study to identify the various factors affecting the quality of the highway projects in Egypt from the local highway owner's and consultant's points of view since they are the ones who supervise the construction process of the highway network in Egypt.

In the present study 39 factors have been introduced and their impact on the quality has been determined through the application of fuzzy triangle approach. Furthermore, questionnaire survey method has been adopted for the purpose of the study. The analysis of the study results shows that the most important factors affecting the quality of highway projects in Egypt as seen from the collective view of the owners of divided highways and main roads, owners of regional roads, and consultants are

(1) availability of experienced staff in the owner's and contractor's teams during the project execution,

(2) efficiency of the owner's inspection team,

(3) clarity of responsibilities and roles for each owner, consultant, and contractor,

(4) pavement is not designed according to the regional conditions (e.g., soil type, temperature, and traffic volume),

(5) asphalt quality and type used in the construction process.

\section{Competing Interests}

The authors declare that there is no conflict of interests regarding the publication of this paper.

\section{References}

[1] M. Abas, S. B. Khattak, I. Hussain, S. Maqsood, and I. Ahmad, "Evaluation of Factors affecting the quality of construction projects," Technical Journal, University of Engineering and Technology (UET) Taxila, Pakistan, vol. 20, no. 2, pp. 115-120, 2015.

[2] J. A. Deacon, C. Monismith, J. Harvey, and L. Popescu, "Pay factors for asphalt-concrete construction: effect of construction quality on agency costs," Technical Memorandum TM-UCBPRC-2001-1, Pavement Research Center, Institute of Transportation Studies, University of California, Berkeley, Calif, USA, 2001.

[3] Transportation Research Board Executive Committee, "NDT technology for quality assurance of HMA pavement construction," NCHRP Report 626, Transportation Research Board, Washington, DC, USA, 2009. 
[4] A. B. Webb, "How to build a quality asphalt pavement," in Solutions for Pavement Rehabilitation Problems, S. Lahue, Ed., pp. 186-202, The American Society of Civil Engineering, New York, NY, USA, 1986.

[5] M. S. Al-Hassan, Factors affecting quality of pavement construction in Saudi Arabia [M.S. thesis], Department of Construction Engineering and Management, King Fahd University of Petroleum and Minerals, Dhahran, Saudi Arabia, 1993.

[6] A. A. Bubshait, "Quality of pavement construction in Saudi Arabia," Practice Periodical on Structural Design and Construction, vol. 6, no. 3, pp. 129-136, 2001.

[7] R. N. Rustom and M. I. Amer, "Modeling the factors affecting quality in building construction projects in Gaza strip," Journal of Construction Research, vol. 7, no. 1-2, pp. 33-47, 2006.

[8] C. Kaliba, M. Muya, and B. Sichombo, "The need to reduce costs, schedule overruns and quality shortfalls in construction," in Proceedings of the 4th Built Environmental Conference, Livingstone, Zambia, 2009.

[9] J. K. Larsen, G. Q. Shen, S. M. Lindhard, and T. D. Brunoe, "Factors affecting schedule delay, cost overrun, and quality level in public construction projects," Journal of Management in Engineering, vol. 32, no. 1, Article ID 4015032, 2016.

[10] K. N. Jha and K. C. Iyer, "Critical factors affecting quality performance in construction projects," Total Quality Management and Business Excellence Journal, vol. 17, no. 9, pp. 1155-1170, 2006.

[11] D. Arditi and H. M. Gunaydin, "Factors that affect process quality in the life cycle of building projects," Journal of Construction Engineering and Management, vol. 124, no. 3, pp. 194-203, 1998.

[12] Timetric, "Construction in Egypt-key trends and opportunities to 2016," 2013, http://www.marketresearch.com/Timetricv3917/Construction-Egypt-Key-Trends-Opportunites-7084362.

[13] I. Farag, SWOT Analysis of Road Transport Sector in the Arab Region, IRU Academy, Alexandria, Egypt, 2012.

[14] PWC's Staff Reporter, "Africa gearing up-future prospects in Africa for the transportation \& logistics industry," 2015, http://www.pwc.com/africagearingup.

[15] C. Kaliba, M. Muya, and K. Mumba, "Cost escalation and schedule delays in road construction projects in Zambia," International Journal of Project Management, vol. 27, no. 5, pp. 522-531, 2009.

[16] World Bank Group, "Proposed road infrastructure and transport development project," Concept Note, Arab Republic of Egypt, World Bank Group, Washington, DC, USA, 2007.

[17] U. Issa, "Developing an assessment model for factors affecting the quality in the construction industry," Journal of Civil Engineering and Architecture, vol. 6, no. 3, pp. 364-371, 2012.

[18] R. H. Abdel-Razek, "Factors affecting construction quality in Egypt: identification and relative importance," Engineering Construction and Architectural Management, vol. 5, no. 3, pp. 220-227, 1998.

[19] R. Abdel -Razek, A. El-Dosouky, and A. Solaiman, "A proposed method to measure quality of the construction project," in Proceedings of the International Exhibition Conference for Building and Construction, Cairo, Egypt, 2001.

[20] R. Tenah, "How is an excellent construction inspection developed," in Quality of Inspection in Search of Excellence, H. Welsh, Ed., pp. 18-31, 1986.

[21] A. Warsame, "Framework for quality improvement of infrastructure projects," Journal of Civil Engineering and Architecture, vol. 7, no. 12, pp. 1529-1539, 2013.
[22] M. Barnes, “Construction project management," International Journal of Project Management, vol. 6, no. 2, pp. 69-79, 1988.

[23] The Massachusetts Highway Department, "Pavement design," in The Massachusetts Highway Department Project Development and Design Guidebook, pp. 9-1-9-28, Mass Highway, 2006.

[24] Transportation Advisory Board, Pavement Design: Concepts \& Sections, Public Works Department, Engineering Services Division, Tulsa, Okla, USA, 2010.

[25] J. M. Knuston, "Building a quality P.C. concrete pavement," in Solutions for Pavement Rehabilitation Problems, S. Lahue, Ed., pp. 165-185, The American Society of Civil Engineering, New York, NY, USA, 1986. 


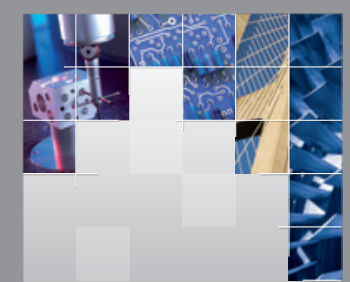

\section{Enfincering}
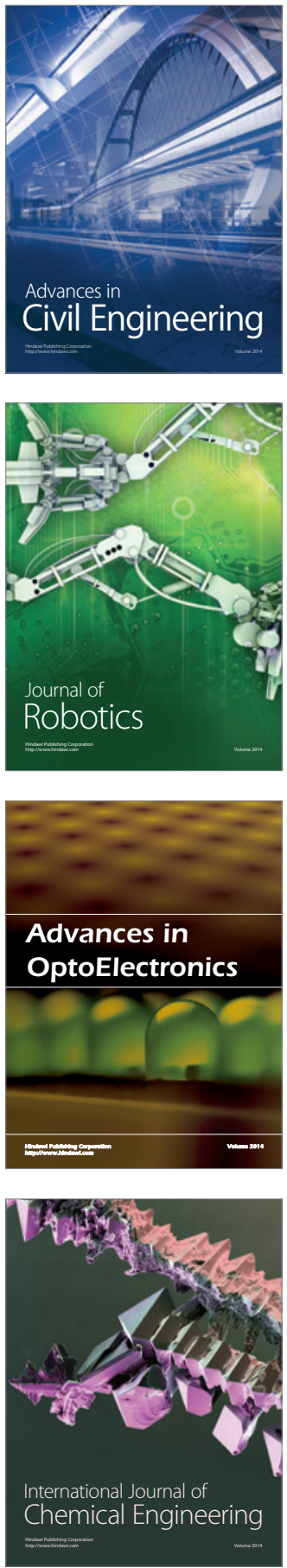

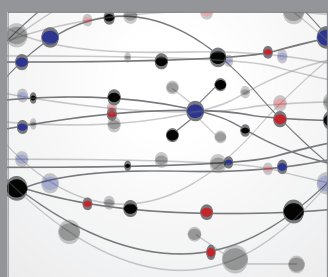

The Scientific World Journal

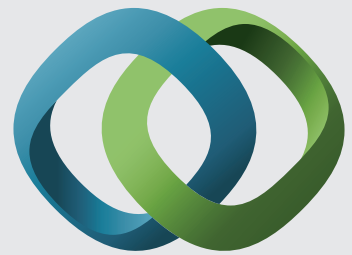

\section{Hindawi}

Submit your manuscripts at

http://www.hindawi.com
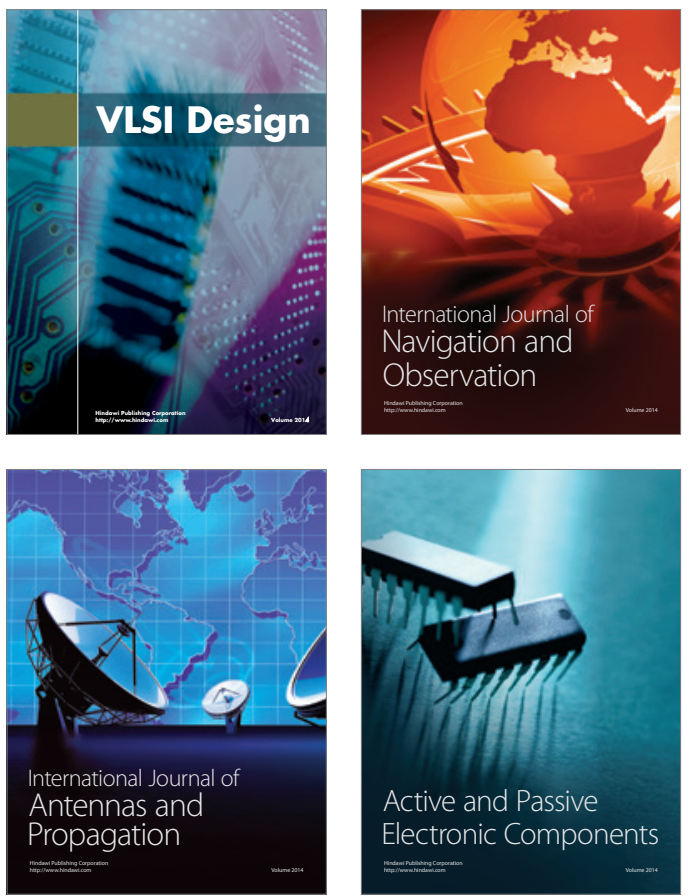
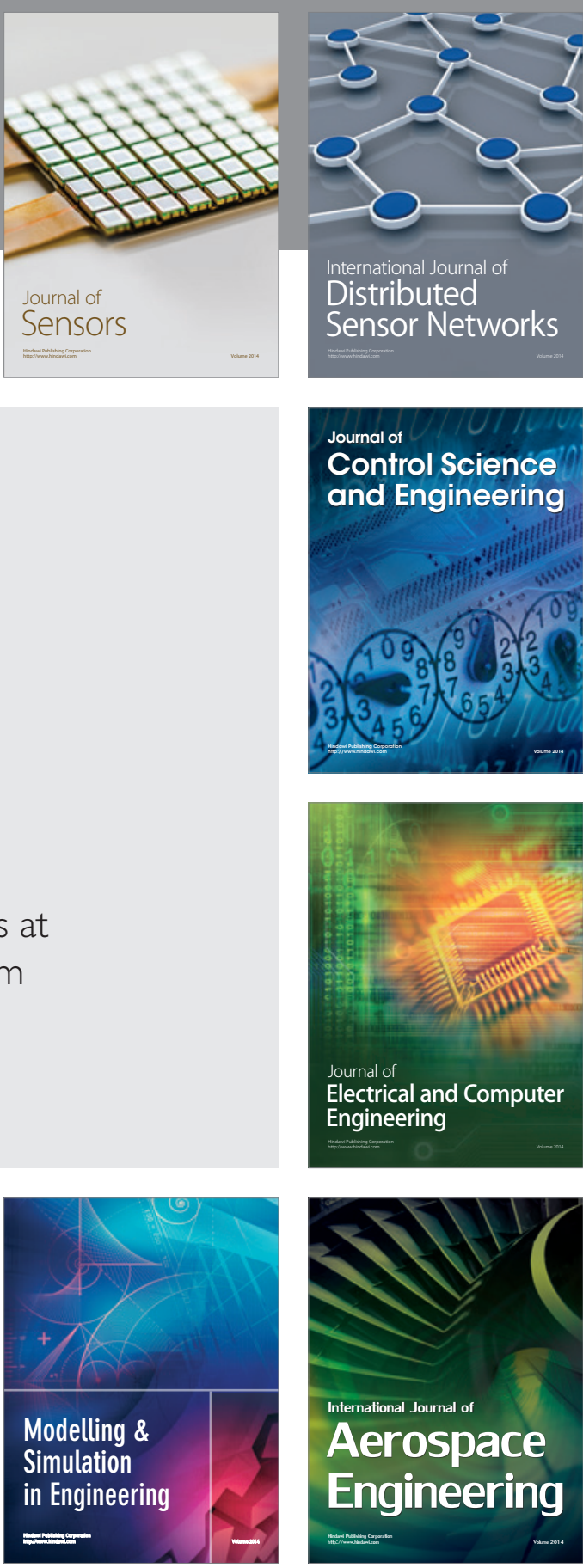

International Journal of

Distributed

Sensor Networks

Journal of

Control Science

and Engineering
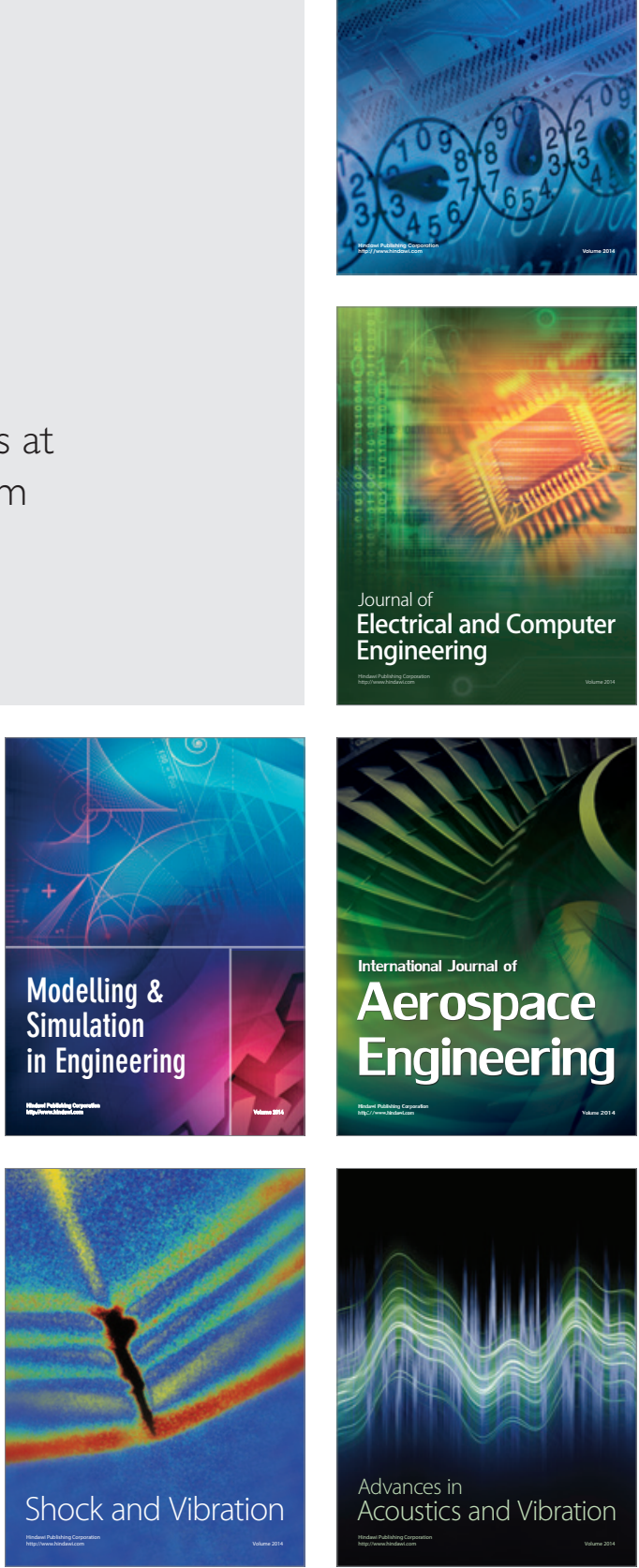